Letrônica, Porto Alegre, v. 7, n. 2, p. 855-867, jul./dez., 2014

\title{
CAMINHANDO PELA VIDA, O DESAFIO DE MAKSIM GÓRKI
}

\author{
WALKING TRHOUGH LIFE, THE CHALLENGE OF MAKSIM GORKI
}

\author{
Luciana Oliveira de Barros*
}

\begin{abstract}
Resumo: Através de um questionamento sobre a possibilidade de reconhecer a frase e a imagem adequadas que se expressam em prosa do escritor russo Maksim Górki, objetiva-se traduzir o vivido que resiste às marcas do mal-estar causado em uma consciência cuja memória foi sua maior singularidade. Propõe-se uma percepção mais aguçada da trilogia autobiográfica Infância, Ganhando meu pão e Minhas universidades, tendo em vista o movimento de ida ao encontro de uma versão própria de um "eu" particular e de uma mundividência única que ratifica e muitas vezes retifica a base histórica que no passado a circunscreveu.
\end{abstract}

Palavras-chave: Literatura Russa; Maksim Górki; Autobiografia.

Abstract: Through a questioning about the possibility to recognize the appropriate phrase and image that are expressed in Maksim Gorki's prose, it is our objective to translate the lived experiences that resist the marks of the uneasiness caused in a conscience whose memory was its greatest uniqueness. We propose a more accurate perception of the autobiographic trilogy $M y$ Childhood, In the World and My Universities, regarding a movement towards a self-account of his own particular "I" and a singular worldview that ratifies and very often rectifies the historical basis that circumscribed it in the past.

Keywords: Russian Literature; Maksim Gorki; Autobiography.

Desde os dez anos tenho vivido às minhas próprias custas, nunca pude estudar, sempre devorei a vida e trabalhei, e a vida ia me esquentando com murros, alimentando-me do bom e do mau. Finalmente me aqueceu e me pôs em movimento. E eis que disparo. Mas embaixo de mim não há trilhos; sinto com frescor e com alguma força, mas não sei pensar (GÓRKI). ${ }^{1}$

\footnotetext{
* Doutora em Letras pela Universidade Federal do Rio de Janeiro - UFRJ. Atualmente, é aluna do PósDoutorado em Letras pela UFRJ, na habilitação em Poética e ligada ao projeto de pesquisa "A poiesis e a construção da realidade e do homem na pós-modernidade", orientado por Manuel Antônio de Castro. Professora da Universidade Estácio de Sá - UNESA.

${ }^{1}$ Essa epígrafe é um trecho de uma carta escrita por Górki para Tchékhov, entre 6 e 15 de janeiro de 1899.
} 
Este artigo tem como objetivo apresentar aos leitores uma das muitas facetas do escritor russo Maksim Górki que vem sendo, aos poucos, conhecido mais detalhadamente pelo público brasileiro.

Sabe-se que Maksim Górki é o pseudônimo de Aleksiei Maksímovitch Piechkóv, o nome falso mais famoso da literatura russa. Aqui trataremos de uma obra de Górki que não é a mais conhecida e nem a mais popular, porém, é muito oportuna. 0 investimento na trilogia Infância, Ganhando meu pão e Minhas universidades vem do destaque dos méritos que ela tem de produzir a ilusão de que estamos diante de um conjunto de fatos reais e concretos contados sem nenhuma espécie de mediação. Entretando, não podemos nos esquecer de que um indivíduo real às vezes diz a verdade e outras vezes finge, até em relação a si próprio. Devido a esse processo, o impacto do valor da autobiografia gorkiana é diretamente proporcional ao seu maior ou menor poder de convicção que é, via de regra, fundamental para o estabelecimento de um pacto autobiográfico entre autor e leitor, pois não há nada mais crível do que a vida de uma pessoa contada por ela mesma.

A análise de uma viagem pela vida é um convite para que os leitores não fiquem restritos à obra $A$ mãe, romance mais famoso de Górki, furtando-se ao conhecimento mais largo de grandes obras em prosa desse autor. Ao tomar essa iniciativa, tive o objetivo de apresentar aos leitores "fatos reais" da ficção gorkiana e de proporcionar a todos aqueles que tiverem contato com este artigo uma grande viagem pelo ciclo de uma existência.

O passar dos anos consiste na compreensão das mudanças dos homens ao longo da vida. Na busca dos "porquês" dessas transformações residem aspectos práticos que nos favorecem ao desvendar uma autobiografia, tais como: a percepção de mundo por meio de nossas sensações e o traquejo no controle desses altos e baixos que forçosamente ocorrem. Devagar, o tempo e o crescimento estabelecem os contornos de uma moral sensitiva e modeladora de condutas. Ao refletir de maneira autobiográfica, Górki escreve das alturas com um olhar que sobrevoa a realidade e a vê conjuntamente com imagens que se referem a uma forma de entender o seu trabalho como observador. Na trilogia é proposta uma literatura que desmistifique um pouco da história da Rússia. Para isso, o tempo não se porta como opressor da imaginação, mas sim como um elemento decisivo e aglutinador de sentido. 
Em uma primeira análise, o foco gorkiano investe na verossimilhança e não na facticidade. A voz do "eu" gorkiano é a voz do menino Aleksiei Piéchkov, de cinco anos, escolhido para contar a sua história, que, do ponto de vista intelectual, seria impossível, considerando que um menino não poderia narrar a sua própria história com tamanha precisão. Na tenra idade, entre os cinco e os dez anos, o menino Aleksiei não deixa claro se os fatos narrados, principalmente em Infância e Ganhando meu pão, remetem ao autor, pois Górki, habilmente, não permite que os fatos embranqueçam ou se diluam e revive sua infância através da lembrança com relatos adequados à linguagem infantil.

Ao nos apresentar as circunstâncias que marcaram a sua infância a partir da morte do pai, o menino-narrador introduz na história figuras típicas russas e estereótipos que serão dissecados durante o seu crescimento (leia-se: durante a evolução da narrativa). Percebe-se claramente que as descrições de Górki são produtos de ficcionalização. São muitos detalhes inseridos numa linguagem poética que sofre uma brusca interrupção causada por relatos mais simples e mais dinâmicos, marcados pela reação do menino frente ao sofrimento.

A autobiografia gorkiana assimila a presença da imaginação e torna tolerável a convivência com o não saber. E são essas incertezas que constroem a sua ficcionalidade. Se a ficção questiona, indaga, poucas explicações oferece e nós continuamos lendo, isso talvez signifique que sejamos o centro de uma ambiguidade, de uma falta de "verdade" restauradora da vida. Para fazer com que a história russa continuasse disponível e aberta, Górki surge como um sujeito que solicitou constantemente um passado marcado no corpo, nas vivências e nas falas. Esse sujeito inventado, Maksim Górki, acabou por se tornar um arqueólogo ficcional sempre em busca das consciências que não deixaram que os seus relatos fossem a única forma legítima de encontrar a verdade.

Nas narrativas, o decorrer do tempo do discurso é gerado pela dimensão psicológica de Aleksiei. 0 tempo filtrado pelas vivências dele serve de referencial da mudança dos fatos ocorridos. Os acontecimentos são mostrados pela voz narrativa sem uma sequência lógica, pois ao mesmo tempo em que está no passado, relatando as suas aventuras de infância, o menino avança para o presente com o pensamento já modificado pelas agruras da vida e até salta para o futuro na tentativa de prever como seria dali a alguns anos. 
Eu tinha uma atração pelo Volga, pela música da vida do trabalho; essa música até hoje embriaga de prazer o meu coração, tenho uma lembrança bonita do dia em que experimentei pela primeira vez a poesia heróica do trabalho.

(...) E o turbilhão pegava os sacos, carregava, jogava, corria de novo e pegava mais um, e me parecia que eu mesmo e todos à minha volta começávamos a girar numa dança tempestuosa, me parecia que aquelas pessoas podiam trabalhar daquela maneira terrível e alegre sem se cansar, sem se poupar - durante meses, durante anos. (...)

Passei aquela noite numa alegria que nunca havia experimentado, o desejo de viver a vida inteira naquele êxtase de atividade meio louco iluminou a minha alma. Ondas dançavam junto às bordas, a chuva chicoteava os conveses, o vento assoviava sobre o rio na bruma cinzenta do amanhecer, homens seminus e molhados corriam de modo impetuoso e incansável, e gritavam, riam, deliciados com a própria força, com o próprio trabalho (GÓRKI, 2007b, p. 40-42).

O decurso temporal sendo de ordem psicológica, temos uma narrativa de vida fragmentária, porém, com grande interação com a história. Minhas universidades, o último volume da trilogia, por exemplo, instaura algumas discussões acerca do destino russo e das prováveis consequências dos desdobramentos de uma revolução russa que batia à porta. Górki utiliza a ficção sem se desvencilhar das próprias experiências e vai tecendo comentários bastante críticos, contando com o seu narrador fictício como porta-voz.

Seria pretensioso demais definir o tempo, no entanto, vale lembrar que os momentos conflituosos dos personagens de Górki nos fazem compreender o vai-e-vem do tempo da memória. A vida acidentada do autor cria uma brecha temporal que destrói completamente a linearidade dos fatos e dá complexidade ao texto. Assim, Aleksiei transpõe a frágil linha do espaço e do tempo e utiliza a memória interior para narrar suas vivências e deixar clara a sua maneira de sentir.

O sonho frustrado de ingressar em uma universidade inicia o terceiro livro da autobiografia. Essa decepção é mais um ponto de retomada em meio a tantas lembranças conflituosas do narrador. Por isso, o fluxo do tempo do discurso é gerado pela dimensão do tempo psicológico. Dessa forma, Aleksiei vai desfiando a história, onde o presente recua para o passado, que volta novamente para o presente e a qualquer momento levando para um futuro bem próximo.

Pois bem, - quem diria, lá fui eu para estudar na universidade de Kazan.

Quem incutiu em mim a ideia da universidade foi N. Evréinov, estudante do liceu, um jovem simpático, bonito, com os olhos carinhosos de mulher. Morava no sótão 
da mesma casa que eu, muitas vezes me via com um livro na mão, isso despertou o interesse dele, fizemos amizade e Evréinov tratou logo de me convencer de que eu era dotado de "faculdades excepcionais para a ciência" (...) Evréinov disse que, em Kazan, eu ia morar na casa dele, faria o curso do liceu durante o outono e o inverno, prestaria "um ou outro" exame (...), na universidade me dariam uma bolsa de estudos e depois de cinco anos eu seria um sábio. Tudo era muito simples porque Evréinov tinha dezenove anos e um bom coração. (...)

- Para que o senhor veio [perguntou a mãe de Evréinov a Aleksiei]?

- Estudar, na universidade.

- (...) 0 senhor descasca bem as batatas.

Ora, como poderia não saber? E lhe contei do meu trabalho no navio a vapor. Ela perguntou:

- O senhor acha que isso é o bastante para entrar na universidade?

(...) 0 excelente rapaz [Evréinov] desejava com sinceridade fazer de mim um homem, prometia-me isso com toda a convicção, mas não tinha tempo nem as demais condições necessárias para ocupar-se de mim a sério. 0 egoísmo e a leviandade da juventude não lhe permitiam ver com que força renhida, com que astúcia, a sua mãe cuidava dos assuntos domésticos. (...) Quanto a mim, fazia tempo que eu conhecia muito bem os complicados truques da química e da economia da cozinha, eu percebia muito bem a habilidade da mulher, diariamente obrigada a enganar o estômago dos filhos e ainda alimentar um rapaz de fora [Aleksiei]. (...) Era natural que cada pedaço de pão que eu recebesse caísse na minha alma como uma pedra. Comecei a procurar algum trabalho, qualquer um. Eu saía de casa, de manhã, para não almoçar ali, mas quando o tempo estava ruim eu ficava no terreno baldio, dentro do porão. Ali, sentindo o cheiro dos cadáveres dos gatos e cachorros, sob o rumor da chuvarada e o suspiro do vento, logo percebi que a universidade era uma fantasia e que eu agiria de modo mais sensato se partisse para a Pérsia (GÓRKI, 2007c, p. 21-23).

O tempo gorkiano, a meu ver, pode sim ser compreendido como psicológico, pois os momentos lembrados pela memória de Aleksiei são a válvula que ejeta toda a subjetividade do narrador. Na trilogia, Górki faz muitas mudanças espaço-temporais e mostra mãos hábeis para colocar a sua existência e a de Aleksiei em paralelo, aproximando aparentemente os trinta anos que separavam as lembranças do menino (que eram o tempo da alma) das páginas escritas pelo autor (que viraram a trama). Segundo José Barros (2011),

Entre o "tempo lógico" de Aristóteles e o "tempo da alma" de Santo Agostinho, Ricoeur irá construir a sua própria proposta de uma interação de perspectivas para a narrativa histórica. Estes dois modelos de tempo, o tempo exterior da intriga e o tempo interior da alma, são os dois pólos a serem colocados em interação pela narrativa histórica proposta por Paul Ricoeur, que busca acomodar o tempo interno agostiniano à intriga aristotélica. (p.5) 
Tudo o que aconteceu no tempo interior de Aleksiei tem a duração que deseja a voz narrativa e transcorre no momento desejado, pois a não marcação do tempo cronológico caracteriza o psicológico. Vejamos, à guisa de ilustração, uma observação de Anton Tchékhov, contista e dramaturgo russo, em resposta à declaração de Górki ao assumir ter sido um sujeito errante.

Sobre a vida errante. Isto, ou seja, a vida errante, é uma coisa boa e atraente, mas com os anos, de certo modo, a gente se torna pesada e gruda ao lugar. E a própria profissão literária, em si, é absorvente. No meio de fracassos e desenganos, o tempo passa rapidamente, não se percebe a vida presente, e o passado, quando eu era tão livre, parece que já não é meu, mas de um estranho (ANGELIDES, 2001, p. 68). ${ }^{2}$

O presente contido na trilogia (lê-se o cotidiano de Aleksiei) fez com que Górki não tenha o seu passado destacado de seu interior e nem completado num futuro. A memória é jogada num presente que ainda se desenvolve. Ainda segundo Ricoeur (apud BARROS, 2011), vale salientar que a experiência do tempo se dá pela busca de uma referência num espaço conhecido, algo gravado na alma como lembrança. Assim, o que há é a expectativa (de algo futuro), a atenção (ao que é) e a memória presente de algo que passou. E, é justamente essa noção de tempo psicológico que facilita o entendimento da estrutura temporal na narrativa gorkiana.

Dentro das lembranças nem sempre ordenadas está presente a relação com todos os personagens que povoaram a vida de Górki ao longo da narrativa. Os retalhos que saem da mente de Aleksiei fazem um cruzamento de tempos e locais com uma dor moral que aumenta e que impede uma linearidade de pensamentos.

Sozinho eu vagava pelos corredores e recantos da Marússovka, observando como viviam as pessoas novas para mim. A casa estava repleta daquelas pessoas e parecia um formigueiro. Pairava um cheiro azedo, corrosivo, e sombras densas, hostis, escondiam-se por todos os cantos. Desde a manhã até tarde da noite, a casa bramia; as máquinas de costura matraqueavam sem parar, as coristas de opereta punham a voz à prova, o estudante arrulhava escalas no registro de baixo, o ator semilouco e embriagado declamava em voz alta, as prostitutas, de ressaca, berravam histéricas, e me ocorria a pergunta natural, mas insolúvel:

"Para que tudo isso?" (GÓRKI, 2007c, p. 33).

\footnotetext{
2 Palavras escritas em uma carta de Tchékhov a Górki, datada de 3 de janeiro de 1899.
} 
Enquanto Aleksiei caminha pelo mundo russo, o seu olhar seleciona objetos e sensações que serão transformados em palavras por Górki que, mesmo sendo o "dono" dessas lembranças, não se preocupou em exprimir a verdade do instante. A sensação de retorno ao passado desencadeia evocações descontroladas que ora recuam e ora avançam, justificando as imagens espontâneas do autobiógrafo.

- É o seu destino...

"É isso", pensei, "alguém também me arrasta, me empurra para cantos ruins, me mostra coisas sórdidas, tristes, e pessoas de matizes estranhos. Estou cansado de tudo isso".

Talvez não tenha pensado com tais palavras, mas exatamente essa ideia se acendeu no cérebro, exatamente naquela noite angustiante senti pela primeira vez um cansaço do espírito, um mofo corrosivo no coração. A partir de então, passei a me sentir pior, comecei a olhar para mim mesmo como a um estranho, friamente, com olhos hostis e alheios.

Eu via que em quase todas as pessoas combinavam-se, de modo canhestro e embaraçoso, contradições não só nas palavras e nas ações, mas também nos sentimentos, e o seu jogo caprichoso me oprimia de forma especialmente aflitiva. Eu era arrastado em todas as direções - para as mulheres e para os livros, para os operários e para os estudantes alegres, mas eu estava sempre deslocado e não vivia "nem lá, nem cá", rodava que nem um pião, enquanto uma mão invisível, mas forte, me fustigava freneticamente com um azorrague invisível (GÓRKI, 2007c, p. 109).

$\mathrm{Na}$ trilogia autobiográfica, esse jogo espaço-temporal subitamente expressa um possível desnorteamento do narrador. Em plena ebulição do pensamento revolucionário, a narração entrecortada dos fatos não deixa Aleksiei estabelecer uma linearidade. 0 coeficiente disso são as falas interrompidas cheias de impressões próprias com a intenção de dar algo de concreto à abstração caótica dos instantes.

0 texto gorkiano causa dúvidas aos leitores quanto à veracidade dos fatos, uma vez que a sua voz se apresenta cambiante ao fazer uma junção entre o presente, o passado e o futuro. Mesmo que Aleksiei se apresente confuso diante da vida e conduza a narrativa baseada na recordação e nos sentimentos de Górki, vamos conhecer, de qualquer maneira apenas uma versão dos fatos, certamente manipulada.

Minha avó morreu. Eu soube da sua morte sete semanas depois do enterro, por meio de uma carta enviada por um de meus primos. Na breve carta - sem vírgulas -, ele contava que a avó caiu quando estava pedindo esmolas no átrio de uma igreja e quebrou a perna. No oitavo dia, "pegou o fogo de Santo Antônio"3. Mais tarde, eu

\footnotetext{
${ }^{3}$ Gangrena.
} 
soube que os dois primos, a irmã deles e seus filhos - gente jovem, saudável viviam à custa da velha, comiam com as esmolas que a avó arrecadava. Nem passou pela cabeça deles chamar um médico.

Na carta dizia:

"Enterramos a avó no cemitério Pedro e Paulo onde todos os nossos familiares acompanharam a gente e também os mendigos eles gostavam dela e choraram. 0 avô também chorou nos enxotou e ficou lá na sepultura a gente olhou de trás dos arbustos como chorava ele também vai morrer logo".

Não chorei, apenas - eu me lembro - foi como se um vento me envolvesse (...)

Recordei aqueles dias muitos anos depois, quando li um conto muito verdadeiro de A. P. Tchékhov sobre um condutor de carroça que conversava com um cavalo a respeito da morte de seu filho (GÓRKI, 2007c, p. 79).

Essa oscilação do narrador é compreensível, haja vista que a memória fervilhante de Aleksiei provoca lembranças desorganizadas em contraste com as impressões precisas do presente de Górki-autor. Durante a narrativa, a variedade dos pensamentos confere a Aleksiei um deslizar nos três tempos verbais, indo de um a outro à vontade, à medida que os seus sentimentos afloram. Com isso,

a experiência em primeira mão das duras condições de vida da imensa maioria da população parecia dar uma feição mais sincera à figuração das classes humildes e trabalhadoras em seus textos, mais direta e brutal do que em outros ficcionistas russos. Vinha embasada pelo crivo da autenticidade. O profundo humanismo proverbialmente atribuído à prosa russa de ficção do século XIX, aquele olhar afetivo diante das pequenas vidas sem sentido, de personagens simples e extraviados, porém dotados de um universo interior riquíssimo, de personalidades e desejos complexos [que] apareciam aos leitores de Górki como a renovação de um legado literário grandioso, por via da experiência pessoal. (GÓRKI, 2010, p.17)

A trilogia gorkiana é um texto altamente diferenciado, pois desenvolve um exercício autobiográfico com um poderoso posicionamento indicador de que tanto a história quanto a ficção trabalham com o objetivo de provocar o ato de leitura com a tarefa de refigurar o material que ambos têm em comum, o tempo. 0 ato de ler que direcionou a conduta intelectual de Górki e que aguça a curiosidade de Aleksiei são congregados num momento essencial. Nesses romances, Górki concretiza uma intencionalidade que tem por princípio a refiguração de um tempo comum à história e à ficção.

Depois de tudo o que eu tinha visto, a vida dos bons e ajuizados intelectuais parecia-me enfadonha, sem cor, parecia manter-se à parte da confusão sombria e semilouca que engendrava a rotina pegajosa dos intermináveis dias da semana. Quanto mais atentamente observava, mais inquieto e incomodado eu me sentia. Parecia-me que os intelectuais não se davam conta do seu isolamento na cidadezinha imunda, onde todos se mostravam alheios e hostis a eles (...) e não 
tinham o menor interesse pela questão da importância do papel do indivíduo no processo histórico (GÓRKI, 2007c, p. 205. Grifo meu).

O imaginário gorkiano está ligado às considerações do "ter sido" que, para ele, não significou desprezar o cunho realista das suas memórias, mas aceitar certa configuração do tempo nas considerações históricas ocorridas em determinados períodos de sua vida. Em Górki, a história "reinscreve o tempo da narrativa no tempo do universo", como propõe Paul Ricoeur, em Tempo e narrativa (1994, p. 317). Então, o imaginário representa o principal ponto para a edificação da história, já que para relacionar o tempo vivido ao tempo do mundo foi preciso contar com certos elos que conduzissem essa coexistência de tempos e que a tornassem legível. Para Górki e Zdanov (1971), a imaginação funcionou como um mecanismo para traduzir o seu tempo.

Inventar é extrair de uma soma de dados reais o sentido fundamental que lhe dá uma forma de imagem: assim se faz o realismo. Mas se a esse sentido do dado real se acrescenta, através do impulso da ideia conforme a lógica do desejo, a possibilidade de aperfeiçoar assim a sua imagem, obter-se-á o romantismo (...); trata-se de um impulso útil, dado que ajuda a sugerir o vínculo que une o desejo à realidade. (GÓRKI; ZDANOV, 1971, p.32)

A proximidade entre a história e a ficção fica mais clara no desenrolar das narrativas, pois a "função representativa da imaginação histórica se [aproximou] mais uma vez do ato de se afigurar (...)" (RICOEUR, 1994, p. 332). Inteligentemente, Górki abre espaço para uma sintonia a mais entre a pessoa e a lembrança ao perceber que construía a sua autobiografia fiel a um pensamento detentor de duas matrizes (memórias e criações), que recorrem às mediações imaginárias no processo de reapresentação do tempo, fato que justifica os empréstimos tomados da história pela literatura e vice-versa. 0 preenchimento do tempo gorkiano se apresenta também de forma intuitiva, pois os

detalhes através das obras nas quais Górki colocou-se em cena (como protagonista) refletem as cores mais variadas, os mais diversos meios nos quais viveu. Porém, a sua infância permaneceu impenetrável, como se estivesse enterrada numa espécie de bruma misteriosa e perturbadora.

Frequentemente, admiradores e amigos suplicaram ao escritor para fazer algumas confidências. Eles queriam saber por quais provações ele havia passado, como se formara este autodidata genial, ao mesmo tempo terno e violento, gentil e revoltado. 
Górki sempre se mostrou esquivo a estas curiosidades. Lembranças extremamente dolorosas o impediam de invocar esses momentos longínquos, de desnudar tantas misérias morais, de desvendar tantas crueldades, de reavivar tantas feridas ainda abertas. (GÓRKI, 1923, n.p)

Para que essa relação entre história e ficção na autobiografia fosse nivelada, Górki pôde sempre contar com um "pacto" com a leitura no qual a voz de sua narração atuava em parceria com os leitores implicados em suas rotinas. Talvez,

(...) o motivo de tais deslocamentos no tempo [tenha ocorrido] pela memória de Górki [que] se guiou pela preocupação de ressaltar o significado histórico e das palavras. Detalhes, por vezes ínfimos, são escolhidos e valorizados não por conta de um possível efeito pitoresco. À luz dos trinta anos que separam a redação do livro e os fatos nele narrados, tais pormenores [ganharam] densidade e [deixaram] entrever o seu potencial alcance histórico (GÓRKI, 2007c, p. 12).

Assim, a escrita autobiográfica gorkiana nos provoca ao levantar a hipótese de que "a ficção é quase histórica, tanto quanto a história é quase fictícia" (RICOEUR, 1994, p. 329). Com isso, a interação entre autor e leitor se intensifica a ponto de virar um pacto no momento da leitura onde se encerra a crença ingênua de que os acontecimentos relatados acabam pertencendo somente ao passado da voz narradora. Nesse ponto, o talento de Górki transborda. Ele consegue mostrar que a sua ficção se assemelha à história, lidando com acontecimentos possivelmente irreais como se fossem fatos passados ao mesmo tempo em que revela que a história também se assemelha à ficção, quando relata acontecimentos reais completados pela vivacidade da presença narrativa de Aleksiei.

O "real" de outrora vivido por Górki não é o bem mais precioso de seu texto, mas sim a maneira pela qual o autor visita esse "real" e o apresenta ao público. Estabelecendo um arco no tempo, Górki traz a história russa para dentro de sua ficção, relembrando sua amizade com revolucionários e seu envolvimento com o movimento populista russo, quando se recuperava da tentativa de suicídio. Recordemos, por exemplo, que o populismo foi um fato histórico decisivo para o caráter revolucionário e socialista da Rússia. Górki o recria ao pôr, na voz do amigo Romas, considerações mais elaboradas e melhor avaliadas sobre a situação política vigente. 
Mais tarde, no quarto, enquanto fumava o cachimbo, com as costas largas apoiadas na estufa e de olhos semicerrados, Romas soltava fios de fumaça na própria barba e, compondo lentamente as palavras num discurso claro e simples, disse que já havia percebido, desde muito tempo, como eu desperdiçava inutilmente os anos da juventude.

- O senhor é um homem capaz, teimoso por natureza e, pelo visto, com boas intenções. 0 senhor precisa estudar, sim, é isso, de maneira que os livros não ocultem as pessoas. Um velhinho sectário dizia, com muita razão, "Todo conhecimento vem do homem". As pessoas nos ensinam de maneira mais dolorosa, ensinam com brutalidade, a ciência delas crava na gente com mais força.

Ele dizia algo que eu já sabia, que antes de tudo é preciso despertar a inteligência dos aldeões. Mas, mesmo nas palavras já conhecidas, eu captava um sentido mais profundo, novo para mim.

- Aqueles estudantes falam muito de amor ao povo, mas eu lhe digo o seguinte: é impossível amar o povo. Isso são palavras, o amor ao povo... (...) Amar significa concordar, condescender, não reparar, perdoar. É assim que é preciso aproximar-se de uma mulher. Mas será possível não reparar na ignorância do povo, concordar com os equívocos de seu pensamento, condescender com todas as suas infâmias, perdoar a sua bestialidade? É possível?

- Não.

- Aí está! Vocês lá não param de ler e recitar Nekrássov, mas, sabe, com Nekrássov não se vai muito longe! É preciso convencer o mujique: "Você, meu irmão não é uma pessoa ruim em si mesmo, porém vive de um jeito ruim e não é capaz de fazer nada para que a vida fique melhor, mais fácil. Um animal selvagem talvez cuide melhor de si do que você, o animal se defende melhor. Mas de você, mujique, de você veio tudo: a nobreza, o clero, os sábios, os tsares... todos foram mujiques. Está vendo? Entendeu? Bem, aprenda a viver de um jeito que não possam bater em você (GÓRKI, 2007c, p. 122).

O que vemos é um personagem histórico (que não é o único) migrando para o espaço autobiográfico, fato que reinterpreta uma importante passagem da história russa. A fala de Romas condensa os discursos histórico e fictício, informa sobre o passado e ainda abre uma nova versão sobre o comportamento dos personagens históricos. Assim, temos um Górki do "futuro" com pensamentos amadurecidos que narra um Aleksiei do passado e revisita um momento histórico com um olhar bem mais abrangente do que aquele em tempo real, pois, por exemplo, "não [havia] nenhuma evidência que comprov[asse] a hipótese de que Górki estava particularmente interessado no momento controverso entre marxistas e populistas" (YEDLIN, 1999, p.9). Portanto, toda a amplitude de conhecimento oferecida pela literatura abre uma janela para que se reflita sobre outros saberes.

Diplomado pela vida, Górki fez com que a sua trilogia passasse por um permanente processo de reconfiguração da realidade. 0 tempo foi filtrado pelo sujeito criador e, em razão do seu caráter referencial, acabou se tornando um tempo subjetivo. De certa maneira, 
a autobiografia gorkiana guardou um grau maior de objetividade, uma vez que o real aparece dissolvido pela vivência de alguém que ao escrever valorizou a força do momento.

Gorky é puro autodidacta, um homem que não adquiriu coisa alguma nas escolas, e que se cultivou, a si próprio, nos intervallos do trabalho manual. Emergiu subitamente das baixas camadas populares que descreve. Estes talentos libertos da formação clássica teem por vesês um sabor acre, e impõe-se com força elementar do povo que os envia. (VOGÜE, 1905, p.232)

Contudo, o autodidatismo e o largo conhecimento da história nacional e mundial contribuíram para uma autorreferencialidade que não se pauta apenas na ordem denotativa como mecanismo de referência. Esse processo se destaca através da escrita autobiográfica que põe em evidência as características discursivas de uma viagem pela vida. Uma viagem rica e radical que induz o leitor a se tornar sensível à condição do texto enquanto objeto de um tipo de "autolinguagem" que, perante si, estremece, se desagrega, se indefine ou se fragmenta para se tornar dizível.

\section{Referências}

BARROS, José D’Assunção. Paul Ricoeur e a narrativa histórica. In: História, imagem e narrativas. Universidade Federal Rural do Rio de Janeiro - UFRRJ, n. 12, p. 1-26, abr 2011.

GÓRKI, Maksim. Infância. Trad. Rubens Figueiredo. São Paulo: Cosac Naify, 2007a.

. Ganhando meu pão. Trad. Boris Schnaiderman. São Paulo: Cosac Naify, 2007b.

Minhas universidades. Trad. Rubens Figueiredo. São Paulo: Cosac Naify, 2007c.

GÓRKI, Maksim. A velha Izerguil e outros contos. Trad. Lucas Simone. São Paulo: Hedra, 2010 .

GÓRKI, M.; ZDANOV, A. Literatura, filosofia e realismo. Trad. Serafim Ferreira. Venda NovaAmadora: Torres \& Abreu, 1971.

GÓRKI, Maxime. En gagnant mon pain: Mémoires autobiographiques. Trad. Serge Perky. Paris: Calmann-Levy, 1923.

RICOEUR, Paul. Tempo e narrativa. São Paulo: Papirus, 1994. 3 v. 
VOGÜE, Melchior. Máximo Gorky: A obra e o homem. Lisboa: Tavares Cardoso, 1905.

YEDLIN, Tovah. Maxim Gorky: A political biography. Connecticut: Wesport Press, 1999.

Recebido em junho de 2014.

Aceito em outubro de 2014. 